\title{
How important are the team dynamics in the battle against COVID-19?
}

\author{
Kajal Ruparell ${ }^{1}$
}

Received: 7 August 2020 / Revised: 8 August 2020 / Accepted: 11 August 2020 / Published online: 19 August 2020

(c) Springer-Verlag GmbH Germany, part of Springer Nature 2020

\section{Dear Sirs,}

I am writing in response to the article "Telemedicine for neuromuscular disorders during the COVID-19 outbreak" [1]. I have seen many articles concerning telemedicine which focus on patients rather than the MDT itself. I would like to shift the focus onto how the team dynamics can be improved remotely to create robust management plans for NMD patients. A well-known phenomenon called 'psychological safety' is essential in a team working effectively. Psychological safety is the notion that no one will be punished or humiliated for bringing up ideas, questions or concerns [2].

Psychological safety is essential in healthcare teams as there is evidence that it reduces burnout [3] and improves patient outcomes [4]. Therefore, a speak-up culture may be able to resolve the diagnostic issues as the team can openly discuss solutions. In times, such as this pandemic, teamwork has been essential in the shift to remote consultations whilst maintaining quality of care. Therefore, taking time to ensure the team is running efficiently and members are free to discuss their opinions or concerns, is paramount.

Literature around the facilitators and barriers in healthcare teams emphasises non-verbal communication $[5,6]$ which is more difficult in remote settings. I would like to increase the discussion around facilitating remote MDT meetings whilst maintaining a psychologically safe environment. Some facilitators include actively encouraging participation [7] which can still be done remotely. This may also overcome a common barrier of ineffective communication which occurs in remote meetings when two members speak over each other unintentionally. Interpersonal relationships are another facilitator but building these are difficult in a remote setting. Therefore, virtual social sessions may be something teams can adopt to maintain healthy relationships to maintain an open culture which can allow members to freely discuss their minds.

Kajal Ruparell

k.ruparell@nhs.net

1 Imperial College London, Faculty of Medicine, London, UK
I hope this has got you thinking of tangible actions you can take in your own remote team meetings to ensure everyone is psychologically safe.

Sincerely,

Kajal Ruparell.

Funding This article received no funding.

\section{Compliance with ethical standards}

Conflicts of interest There are no conflicts of interest.

Ethical standard statement No ethical approval was required as there was no primary data collection.

\section{References}

1. Garibaldi M, Siciliano G, Antonini G (2020) Telemedicine for neuromuscular disorders during the COVID-19 outbreak. J Neurol $10: 1-4$

2. Edmondson AC, Kramer RM, Cook KS (2004) Psychological safety, trust, and learning in organizations: a group-level lens. Trust and distrust in organizations. Dilemmas Approach 29(12):239-272

3. Vévoda J, Vévodová Š, Nakládalová M, Grygová B, Kisvetrová H, Grochowska Niedworok E, Chrastina J, Svobodová D, Przecsková P, Merz L (2016) The relationship between psychological safety and burnout among nurses. Occup Med/Pracovní Lékarství 1:68

4. Leroy H, Dierynck B, Anseel F, Simons T, Halbesleben JR, McCaughey D, Savage GT, Sels L (2012) Behavioral integrity for safety, priority of safety, psychological safety, and patient safety: a team-level study. J Appl Psychol 97(6):1273

5. Carmeli A, Brueller D, Dutton JE (2009) Learning behaviours in the workplace: the role of high-quality interpersonal relationships and psychological safety. Syst Res Behav Sci 26(1):81-98

6. Nembhard IM, Edmondson AC (2006) Making it safe: The effects of leader inclusiveness and professional status on psychological safety and improvement efforts in health care teams. J Organ Behav 27(7):941-966

7. Carmeli A, Reiter-Palmon R, Ziv E (2010) Inclusive leadership and employee involvement in creative tasks in the workplace: the mediating role of psychological safety. Creativ Res J 22(3):250-260 